\title{
What are the barriers faced by patients using insulin? A qualitative study of Malaysian health care professionals' views
}

This article was published in the following Dove Press journal:

Patient Preference and Adherence

22 January 2013

Number of times this article has been viewed

\author{
Yew Kong Lee' \\ Chirk Jenn $\mathrm{Ng}^{\prime}$ \\ Ping Yein Lee ${ }^{2}$ \\ Ee Ming Khoo' \\ Khatijah Lim Abdullah ${ }^{3}$ \\ Wah Yun Low ${ }^{4}$ \\ Azah Abdul Samad ${ }^{5}$ \\ Wei Seng Chen ${ }^{6}$ \\ 'Department of Primary Care \\ Medicine, Faculty of Medicine, \\ University of Malaya, Kuala Lumpur, \\ Malaysia; ${ }^{2}$ Department of Family \\ Medicine, Universiti Putra Malaysia, \\ Serdang, Selangor, Malaysia; \\ ${ }^{3}$ Department of Nursing Sciences, \\ Faculty of Medicine, University of \\ Malaya, Kuala Lumpur, Malaysia; \\ ${ }^{4}$ Faculty of Medicine Dean's Office, \\ University of Malaya, Kuala Lumpur, \\ Malaysia; ${ }^{5}$ Klinik Kesihatan Pantai, \\ Kuala Lumpur, Malaysia; ${ }^{6} \mathrm{Klinik}$ Alam \\ Medic, Puchong, Selangor, Malaysia
}

Correspondence: Yew Kong Lee Department of Primary Care Medicine, Faculty of Medicine, University of Malaya, 50603 Kuala Lumpur, Malaysia

Tel +60 379492306

Fax +60 37957 794I

Email leeyk@um.edu.my
Background: Patients with type 2 diabetes often require insulin as the disease progresses However, health care professionals frequently encounter challenges when managing patients who require insulin therapy. Understanding how health care professionals perceive the barriers faced by patients on insulin will facilitate care and treatment strategies.

Objective: This study explores the views of Malaysian health care professionals on the barriers faced by patients using insulin.

Methods: Semi-structured qualitative interviews and focus group discussions were conducted with health care professionals involved in diabetes care using insulin. Forty-one health care professionals participated in the study, consisting of primary care doctors $(n=20)$, family medicine specialists $(n=10)$, government policymakers $(n=5)$, diabetes educators $(n=3)$, endocrinologists $(n=2)$, and one pharmacist. We used a topic guide to facilitate the interviews, which were audio-recorded, transcribed verbatim, and analyzed using a thematic approach.

Results: Five themes were identified as barriers: side effects, patient education, negative perceptions, blood glucose monitoring, and patient adherence to treatment and follow-up. Patients perceive that insulin therapy causes numerous negative side effects. There is a lack of patient education on proper glucose monitoring and how to optimize insulin therapy. Cost of treatment and patient ignorance are highlighted when discussing patient self-monitoring of blood glucose. Finally, health care professionals identified a lack of a follow-up system, especially for patients who do not keep to regular appointments.

Conclusion: This study identifies five substantial barriers to optimizing insulin therapy. Health care professionals who successfully identify and address these issues will empower patients to achieve effective self-management. System barriers require government agency in establishing insulin follow-up programs, multidisciplinary diabetes care teams, and subsidies for glucometers and test strips.

Keywords: primary care, focus groups, noncommunicable disease, diabetes, insulin, qualitative study

\section{Introduction}

Type 2 diabetes affects 366 million people worldwide. This figure is expected to rise to 552 million by $2030 .{ }^{1}$ Insulin remains one of the most effective methods for achieving glycemic control in patients with type 2 diabetes, either alone or in combination with anti-diabetic oral medications. ${ }^{2}$ Despite this, patients are generally reluctant to start insulin therapy. ${ }^{3,4}$ Barriers to starting insulin are well documented in the literature ${ }^{3,5-7}$ and initial reluctance is viewed as the major hurdle in patients with type 2 diabetes.

However, barriers at initiation are only one part of the problem as patients continue to encounter barriers after insulin initiation, ${ }^{7}$ and up to a third of patients admit to 
non-adherence to insulin regimes. ${ }^{8}$ Giving more precise recommendations does not improve adherence rates ${ }^{9}$ as barriers to adherence are related to patient perception and acceptance of insulin therapy. ${ }^{9,10}$ Patients using insulin need to be continuously educated and empowered to self-manage their insulin regiment. ${ }^{11}$ However, this can only be achieved if health care professionals (HCPs) are aware of the problems faced by patients.

Malaysia has the highest prevalence rate of type 2 diabetes $(11.7 \%)$ in the Western Pacific region, and this figure is projected to rise to $13.3 \%$ by $2030 .{ }^{12}$ The majority of patients in Malaysia have poor glycemic control; only about $20 \%$ have $\mathrm{HbA}_{1 \mathrm{c}}$ levels of less than $7 \% .{ }^{13-15}$ This leads to an increase in micro- and macrovascular complications, which impose a heavy burden on the country's already stretched health care system, ${ }^{16}$ in which cardiovascular disease accounts for the highest number of hospital deaths. ${ }^{17}$

Little research has been done on Malaysian HCPs' views of patient barriers to insulin use. Understanding this will create strategies to help HCPs care for patients on insulin therapy. This study therefore aims to explore HCPs' views on the barriers faced by patients using insulin. It is part of a larger 3-year study to develop an intervention to assist in shared decision-making in insulin therapy.

\section{Methods}

\section{Design}

This was a qualitative study using semi-structured individual interviews and focus groups to identify and explore the views of HCPs on the barriers faced by patients using insulin. The in-depth interviews, focus group discussions, and field notes provided the basis for data analysis.

\section{Setting}

Malaysia has a dual-sector health system comprising government-subsidized public health facilities and private fee-for-service clinics and hospitals. The majority of patients with type 2 diabetes are treated in public health facilities as the cost is lower. In public primary care settings, family medicine specialists and medical officers initiate insulin therapy as only doctors are allowed to do so in Malaysia. Diabetes nurse educators provide patient education and follow-up. In the private sector, management of diabetes care is dependent on the doctor, as most clinics are solo practices that do not have support from a diabetes care team or nurse educators. Such disparities in care give rise to different barriers faced by private and public patients.
The sample comprised HCPs who provide diabetes care in the three health care settings in Malaysia: public health clinics (both urban and semi-rural); public university-based primary care clinics and hospitals; and private general practice clinics and hospitals. Key government policymakers who plan national diabetes strategies were also interviewed.

\section{Participants, recruitment, sampling}

Primary and secondary care HCPs who provide diabetes care, including insulin therapy, were recruited using purposive sampling and snowball methods. For recruiting focus groups, we selected participants based on their specialties and their health care system. This was to ensure homogeneity and to capitalize on shared experiences. ${ }^{18}$ Participants of the focus groups comprised two groups of general practitioners working in the private setting $(\mathrm{n}=11)$, trained primary care doctors (family medicine specialists) working in public health clinics $(n=8)$, and untrained primary care doctors (medical officers) from a university-based primary care clinic $(n=8)$. In-depth interviews were conducted for government policymakers and for HCPs who were unable to attend a focus group session due to other commitments. Sample size was determined by data saturation and interviews were stopped when a consensus was reached among three researchers that the data categories were established and that any new data would fit into categories already devised. We also interviewed patients with type 2 diabetes; these study findings will be reported separately.

\section{Data collection}

An interview topic guide was developed based on a literature review, clinical knowledge, and research experience. Participants were asked about diabetes management in general and barriers to insulin use encountered in their clinical experience, including barriers faced by patients. The same guide was used for both individual and focus group discussions. The interviews and focus group discussions were carried out by one of the four researchers, who are trained to conduct qualitative interviews. Care was taken to avoid interviews being conducted by close acquaintances of the participants to prevent potential response bias. A research assistant took detailed notes and observations of nonverbal cues during the interviews, which were used as field notes. From October 2010 to May 2011, we conducted 14 individual interviews, each lasting 30 to 40 minutes, and held four focus group discussions, each of which lasted for 1 hour. All interviews and focus group discussions were audiotaped and transcribed verbatim. Each transcript was checked for accuracy by another transcriber and used as data for analysis. 


\section{Data analysis}

The researchers first scrutinized the data before applying a thematic analysis approach to identify the main themes. To maximize the validity of the analytical interpretations, three researchers independently coded two transcripts to determine the coding frame. This framework was then used to code two other transcripts individually. Any coding discrepancies were resolved by discussion until a consensus was reached. The final list of nodes was used as a framework for coding the rest of the transcripts. New nodes emerging during coding were added to the list upon consultation with other researchers. Nvivo9 software (QSR International Pty Ltd, Doncaster, Victoria, Australia) was used for data analysis. The list of nodes was regrouped into larger categories as themes emerged from the data. This systematic approach to the analysis contributes to the establishment of an "audit trail" from the transcripts of raw data through to the final interpretation.

Researchers analyzing the data were family medicine specialists and psychologists. They reflected and debated on the potential biases to improve the credibility of the analysis.

\section{Ethics approval}

This study received ethics approval from the Medical Research and Ethics Committee, Ministry of Health, Malaysia (reference: NMRR-10-1233-7299).

\section{Results}

Forty-one HCPs involved in the care of patients using insulin participated in the study (see Table 1 for demographic characteristics). A descriptive model emerged from the thematic analysis, where HCPs identified five types of challenges faced by patients: issues related to side effects, patient education, negative perceptions, self-monitoring of blood glucose, and follow-up of patients. (Illustrative quotes are reported verbatim.)

\section{Side effects of insulin}

HCPs view side effects experienced by insulin users, such as weight gain and hypoglycemia, as a challenge. Severe episodes of hypoglycemia are traumatic enough to stop patients from using insulin altogether:

If you highlight the weight gain, it's gonna be a big barrier to it. So, um ... the subject of weight gain usually comes about once they're on insulin already. Because unavoidably, you mention weight every visit and then you see the weight going up every visit, the more the insulin, the more the weight, then you have to tell them ... very quickly, you say "side effects of insulin.” [Endocrinologist, public tertiary care hospital]
Table I Demographic profile of participants

\begin{tabular}{llll}
\hline Characteristics & $\begin{array}{l}\text { Number } \\
(\mathbf{n}=\mathbf{4 I})\end{array}$ & $\%$ & $\begin{array}{l}\text { Mean } \pm \text { SD } \\
\text { (range), years }\end{array}$ \\
\hline Age & & & $46.6 \pm 9.8$ \\
& & & $(30-66)$ \\
Sex & 31 & 75.6 & \\
$\quad$ Female & 10 & 24.4 & \\
$\quad$ Male & & & \\
Ethnicity & 15 & 36.6 & \\
$\quad$ Malays & 10 & 24.4 & \\
$\quad$ Chinese & 13 & 31.7 & \\
Indians & 3 & 7.3 & \\
$\quad$ Other & & & \\
Professional background & 20 & 48.8 & \\
$\quad$ Primary care doctor & 10 & 24.4 & \\
$\quad$ Family medicine specialist & 12.2 & \\
$\quad$ Government policy maker & 5 & 7.3 & \\
$\quad$ Diabetes nurse educators & 3 & 4.9 \\
$\quad$ Endocrinologists & 2 & 2.4 \\
$\quad$ Pharmacist & 1 & 63.4 \\
Health care sector & & 36.6 \\
$\quad$ Public & 26 & \\
Private & 15 & \\
\hline
\end{tabular}

I have a friend who is an $\mathrm{O}$ and $\mathrm{G}$ [obstetrics and gynecology] consultant; he was on insulin. What happened was I think he skipped his breakfast, so he went into hypoglycemic coma while he was driving. So they stopped the car at the traffic lights ... so lucky you know, the passers-by take him to hospital. After that, until now, he refuses to take insulin. [General practitioner, private general practice]

\section{Patient education}

HCPs felt that patients do not receive enough information on adjusting the insulin dose to optimize insulin regimes. In addition, patient education is time consuming:

\begin{abstract}
So ... the most common thing, what happen is, people start insulin, but after that, they don't optimize and specify the regime. The patient who started just on one regime for, like, many years and nobody have actually taught the patient how to do the self-titration of the insulin too ... and that requires more time because you really have to sit down, tell the patient, "Ok, you are now in this regime, this insulin," erm ... "action is for this long." [Family medicine specialist, public health clinic]
\end{abstract}

\section{Negative perceptions about insulin}

HCPs identified negative perceptions that caused patients to discontinue insulin usage. Patients believe that they only need to use insulin when their glucose levels are high, or that they could stop using insulin when they feel better: 
I've seen so many patients who have been given insulin from the hospital; they will come and say, "Doctor, this is given but I'm not using it." Only sometimes they will monitor, when it's high, 25-30, then they will inject themselves. [General practitioner, private general practice]

R1: Maybe they [patients] will continue [using insulin] for a while, they will get better, they said, "No, I don't want injection anymore."

R2: They said "I am better, so I can stop now." [General practitioners, private general practice]

Some patients were reluctant to follow the recommended treatment regime as it was seen as conflicting with their diet and lifestyle:

Maybe [we] can just choose, we [HCPs] cannot give three pre-mixed, you know ... so it depends how their [patients'] lifestyle. It depends on their work also ... how's their working and meal times. Their mealtimes also ... they will tell us. Because when we negotiate, you know, some, they said okay, after negotiating, then they're okay. Then they try to follow. But some they said cannot ... they still want to; they want us to follow them ... to follow their meal times. [Family medicine specialist, public health clinic]

\section{Blood glucose monitoring}

Cost was a deterrent to purchasing a glucometer for self-monitoring of blood glucose (SMBG), especially for patients from less affluent backgrounds:

I think quite many [patients] don't have glucometer ... I don't have the figure, but I think so, because, like I told you ... the majority that comes here is from low and middle class. Sometimes, maybe they give priority to other things. Means ... maybe, actually it's not because they don't have money ... but they maybe used the money for other things first. [Family medicine specialist, public health clinic]

It was difficult for patients to carry out SMBG because glucometers were not provided, even though insulin and pens were subsidized in the public setting. In addition, SMBG kits were not available at certain locations:

How come when we [public health clinics] give all [insulin and pens], we provide everything free, but the glucometer is not given, test strips are not given, and how are they [patients] monitoring the blood glucose? [General practitioner, private general practice]

But you know, when I go and practice in Kuantan and Terengganu, I don't have this [a subsidy scheme for SMBG kits]. You know, I'm lost! And the patients are so bad. You can just imagine how terribly ... these are patients being held up in ... in ... in state hospitals, in specialist clinics. And they've been on insulin for years and they don't monitor their sugar and to start them on is difficult because the resource center has no way that they can get a glucometer, you know. [Endocrinologist, public tertiary hospital]

Other barriers to SMBG are a lack of awareness on the importance of SMBG and the fear of finger pricking:

Those who can afford also don't see that it's important to invest on the glucometer... And then after that is the problem of having the meter, but they're not doing. When we talk about meter and everything, you have to talk about fear of pricking. That's another barrier. [Family medicine specialist, public health clinic]

\section{Lack of continuity of care}

There is a lack of continuity of care in both public and private settings for patients on insulin therapy:

Then the trouble that I've found is that when they're [patients] on [insulin], I don't know what's happening. In fact, sometimes they don't want to see me. They just come and collect medicine. Then I say, "Hey, haven't seen you for a long time, what happened?" [General practitioner, private general practice]

A lot of patients are referred at diagnosis [to tertiary care], at the initiation of insulin, and that's it. So, there's nothing in between, you know. And you know ... you [patients] can't remember everything that people tell in the beginning. So, probably these insulin users should have a regular followup, just like a follow-up with your doctor. [Endocrinologist, public tertiary care hospital]

\section{System change}

The government has changed suppliers of insulin pens, leading to confusion among patients as they need to learn how to use a different type of insulin pen:

So [Company A], got [Pen A]. Then they [the government] give the tender to [Company $\mathrm{B}$ ], we have got no choice just to switch everybody on [Company B] pen. So now, we have both. So, I suppose it's up to doctor. What is most important is actually that if the patient already have one, you start them on bedtime insulin - they already have one pen. So you try to give similar pen, so that they don't get confused. Yeah ... they don't have to learn two different type of pen. [Family medicine specialist, public health clinic] 


\section{Discussion}

This qualitative study helps to shed light on HCPs' views of barriers faced by patients on insulin therapy, which is an area that has been prioritized under recent policy initiatives by the Malaysian Ministry of Health (MOH) for patient adherence in non-communicable diseases. ${ }^{19}$ The government focus is on empowering patients in self-management through inter-personal health education programs run by trained diabetes educators and specifically for diabetes, making available subsidized glucostrips for SMBG.${ }^{19}$ Our study shows that HCPs view the attainment of these targets differently. HCPs highlighted the lack of patient education activities and continuity of care. In addition, SMBG subsidies are still unavailable.

\section{Main findings and comparisons with other studies}

HCPs generally have poor expectations of patient adherence to insulin therapy. Up to $92.3 \%$ of doctors believe that patients would not comply with insulin treatment ${ }^{20}$ and a multinational survey reported that $72.5 \%$ of their patients did not comply with insulin regimes. ${ }^{8}$ Therefore, as documented in our results, it is expected that Malaysian HCPs would report a variety of barriers to insulin use. The results of our study are discussed in comparison with other studies.

HCPs view patients' negative experiences of insulin side effects, especially hypoglycemia, as a major barrier. This is consistent with a recent report that fear of hypoglycemia (FoH) is still a widespread phenomenon, with a significant negative impact on diabetes management, metabolic control, and subsequent health outcomes. ${ }^{21}$ Besides that, although the use of newer insulin analogs reduces the risk of hypoglycemic episodes, ${ }^{22,23}$ cost is a concern. It is important to educate patients on observing regular meals to avoid hypoglycemia and to conduct blood glucose awareness training. ${ }^{24}$ Cognitive behavior therapy ${ }^{25}$ can help reduce patient fears and anxiety associated with fear of hypoglycemia.

Studies elsewhere have also reported that patient misperceptions about increased insulin dosage and disease deterioration are barriers for insulin users. ${ }^{26,27}$ Strategies to overcome these include structured patient education training and follow-up programs. These have been shown to significantly improve the management of diabetes ${ }^{28}$ as well as reduce diabetes-related distress. ${ }^{29}$ However, implementing insulin follow-up and education for patients requires sufficient staff resources. In Malaysia, this translates into training more diabetes nurse educators as there is a severe shortage.

HCPs perceive that patient follow-up is inconsistent or non-existent in some settings. Developing an effective system of follow-up would require the integration of care and follow-up between public and private sectors and the involvement of nongovernment agencies. ${ }^{30}$ Possible strategies include allowing referral of private patients to public sector insulin initiation and follow-up programs, as well as introducing shared care between the two sectors to reduce the disproportionately heavy workload faced by the public sector. ${ }^{30}$

The cost of SMBG kits was highlighted as a barrier. Thus, it is encouraging that providing financial support for SMBG has been identified as a key public policy initiative for diabetes. ${ }^{19}$ In Malaysia, the cost of insulin and pens are subsidized in public settings, but SMBG kits and test strips are out-of-pocket expenses for patients. However, the proposed subsidy for glucostrips has yet to be implemented in practice. Currently, patients receive financial assistance in the form of discounted glucometers from companies; however, patients are still required to pay out-of-pocket for glucostrips. Feedback from private sector HCPs suggests that access to public sector support for SMBG should be extended to patients in private health care as cost is also a concern for them. Another challenge related to public policy and practice is the awarding of contracts to companies to supply insulin and insulin pens to public health clinics as the majority of patients with chronic conditions are treated in public facilities. ${ }^{31,32}$ The change in insulin pens can cause confusion among patients who need to learn how to use the new pen. Options should be made available to allow patients to continue using the pen they are familiar with.

\section{Strengths and limitations}

This study's strength is that the sample comprises a broad spectrum of settings and professionals involved in diabetes care. Thus, researchers are able to gain an in-depth understanding of the challenges to insulin use from HCPs from different settings. As an exploratory study, the results indicate that HCPs are aware of the problems faced by patients. More research is needed to study the prevalence and severity of these barriers. Such information would ensure that barriers to patient adherence to insulin can be addressed before, during, and even after insulin initiation, such as in the case of patients who discontinue use due to anxiety and require counseling.

One limitation of this study is that only HCPs' views on patient barriers were explored. Patient perspectives will be explored as part of a larger study and compared with challenges identified by HCPs.

\section{Conclusion}

This study discusses barriers faced by patients using insulin after initiation. Issues such as fears, misperceptions, and side effects can be substantial barriers and HCPs who successfully 
identify and address these issues can empower patients to achieve effective self-management. Overcoming system barriers requires government initiative to establish insulin follow-up programs, multidisciplinary diabetes care teams, and subsidies for glucometers and test strips.

\section{Acknowledgments}

This study was funded by a research grant from the University of Malaya, Malaysia (reference: UMRG 236/10HTM). We would like to acknowledge Professor CL Teng and Ms Syahidatul Akmal Azmi for their assistance in arranging the interviews and focus group discussions. We would like to thank the Ministry of Health for allowing their staff to participate in this study.

\section{Disclosure}

The authors report no conflicts of interest in this work.

\section{References}

1. Whiting DR, Guariguata L, Weil C, Shaw J. IDF Diabetes atlas: global estimates of the prevalence of diabetes for 2011 and 2030. Diabetes Res Clin Pract. 2011;94(3):311-321.

2. Ponssen HH, Elte JW, Lehert P, Schouten JP, Bets D. Combined metformin and insulin therapy for patients with type 2 diabetes mellitus. Clin Ther. 2000;22(6):709-718.

3. Polonsky WH, Fisher L, Guzman S, Villa-Caballero L, Edelman SV. Psychological insulin resistance in patients with type 2 diabetes: the scope of the problem. Diabetes Care. 2005;28(10):2543-2545.

4. Wong S, Lee J, Ko Y, Chong MF, Lam CK, Tang WE. Perceptions of insulin therapy amongst Asian patients with diabetes in Singapore. Diabet Med. 2011;28(2):206-211.

5. Lee YK, Lee PY, Ng CJ. A qualitative study on health care professionals' perceived barriers to insulin initiation in a multi-ethnic population. $B M C$ Fam Pract. 2012;13(1):28.

6. Korytkowski M. When oral agents fail: practical barriers to starting insulin. Int J Obes Relat Metab Disord. 2002;26 Suppl 3:S18-S24.

7. Guimaraes C, Marra CA, Gill S, et al. Exploring patients' perceptions for insulin therapy in type 2 diabetes: a Brazilian and Canadian qualitative study. Patient Prefer Adherence. 2010;4:171-179.

8. Peyrot M, Barnett AH, Meneghini LF, Schumm-Draeger PM. Insulin adherence behaviours and barriers in the multinational Global Attitudes of Patients and Physicians in Insulin Therapy study. Diabet Med. 2012;29(5):682-689.

9. Lerman I, Diaz JP, Ibarguengoitia ME, et al. Nonadherence to insulin therapy in low-income, type 2 diabetic patients. Endocr Pract. 2009; 15(1):41-46.

10. Peyrot M, Barnett AH, Meneghini LF, Schumm-Draeger PM. Factors associated with injection omission/non-adherence in the Global Attitudes of Patients and Physicians in Insulin Therapy study. Diabetes Obes Metab. Epub 2012 Jun 21.

11. Rakel RE. Improving patient acceptance and adherence in diabetes management: a focus on insulin therapy. Adv Ther. 2009;26(9):838-846.

12. International Diabetes Federation [homepage on the Internet]. IDF Diabetes Atlas - Fifth edition. Brussels: International Diabetes Federation; 2011. Available from: http://www.idf.org/atlasmap/atlasmap. Accessed July 3, 2012.
13. Ismail $\mathrm{M}$, Chew $\mathrm{B}$, Lee $\mathrm{P}$, et al. Control and treatment profiles of 70,889 adult type 2 diabetes mellitus patients in Malaysia: a cross sectional survey in 2009. International Journal of Collaborative Research on Internal Medicine and Public Health. 2011;3(1):98-113.

14. Mafauzy M. Diabetes control and complications in private primary health care in Malaysia. Med J Malaysia. 2005;60(2):212-217.

15. Chan GC, Ghazali O, Khoo EM. Management of type 2 diabetes mellitus: is it in accordance with the guidelines? Med J Malaysia. 2005;60(5):578-584.

16. Clarke PM, Glasziou P, Patel A, et al. Event rates, hospital utilization, and costs associated with major complications of diabetes: a multicountry comparative analysis. PLoS Med. 2010;7(2):e1000236.

17. Ministry of Health. Health Facts 2010. Putrajaya: Ministry of Health, Malaysia; 2010.

18. Kitzinger J. Qualitative research. Introducing focus groups. BMJ. 1995;311(7000):299-302

19. Ministry of Health. National Strategic Plan for Non-Communicable Disease (NSPNCD) Medium Term Strategic Plan to Further Strengthen The Cardiovascular Diseases and Diabetes Prevention and Control Program in Malaysia (2010-2014). Putrajaya: Ministry of Health, Malaysia; 2010.

20. Nakar S, Yitzhaki G, Rosenberg R, Vinker S. Transition to insulin in type 2 diabetes: family physicians' misconception of patients' fears contributes to existing barriers. J Diabetes Complications. 2007;21(4): 220-226.

21. Wild D, von Maltzahn R, Brohan E, Christensen T, Clauson P, Gonder-Frederick L. A critical review of the literature on fear of hypoglycemia in diabetes: implications for diabetes management and patient education. Patient Educ Couns. 2007;68(1):10-15.

22. Philis-Tsimikas A, Charpentier G, Clauson P, Ravn GM, Roberts VL, Thorsteinsson B. Comparison of once-daily insulin detemir with NPH insulin added to a regimen of oral antidiabetic drugs in poorly controlled type 2 diabetes. Clin Ther. 2006;28(10):1569-1581.

23. Riddle MC, Rosenstock J, Gerich J. The treat-to-target trial: randomized addition of glargine or human NPH insulin to oral therapy of type 2 diabetic patients. Diabetes Care. 2003;26(11):3080-3086.

24. Cox DJ, Gonder-Frederick L, Polonsky W, Schlundt D, Kovatchev B, Clarke W. Blood glucose awareness training (BGAT-2): long-term benefits. Diabetes Care. 2001;24(4):637-642.

25. Boyle S, Allan C, Millar K. Cognitive-behavioural interventions in a patient with an anxiety disorder related to diabetes. Behav Res Ther. 2004;42(3):357-366.

26. Larkin ME. Overcoming psychological barriers to insulin use. US Endocrinol. 2009;4(II):46-48.

27. Larkin ME, Capasso VA, Chen C-L, et al. Measuring psychological insulin resistance: barriers to insulin use. Diabetes Educ. 2008;34(3):511-517.

28. Chen SY, Chang YH, Hsu HC, Lee YJ, Hung YJ, Hsieh CH. One-year efficacy and safety of the telehealth system in poorly controlled type 2 diabetic patients receiving insulin therapy. Telemed J E Health. 2011; 17(9):683-687.

29. Hermanns N, Kulzer B, Maier B, Mahr M, Haak T. The effect of an education programme (MEDIAS 2 ICT) involving intensive insulin treatment for people with type 2 diabetes. Patient Educ Couns. 2012;86(2):226-232.

30. Lee PY, Lee YK, Ng CJ. How can insulin initiation delivery in a dual-sector health system be optimized? A qualitative study on health care professionals' views. BMC Public Health. 2012;12(1):313.

31. Clinical Research Centre. National Healthcare Establishments \& Workforce Statistics (Primary Care) 2008-2009. Kuala Lumpur: Ministry of Health, Malaysia; 2011.

32. Ramli AS, Taher SW. Managing chronic diseases in the Malaysian primary health care: a need for change. Malaysian Family Physician. 2008;3(1):7-13. 
Patient Preference and Adherence

Dovepress

\section{Publish your work in this journal}

Patient Preference and Adherence is an international, peer-reviewed, open access journal focusing on the growing importance of patient preference and adherence throughout the therapeutic continuum. Patient satisfaction, acceptability, quality of life, compliance, persistence and their role in developing new therapeutic modalities and compounds to optimize clinical outcomes for existing disease states are major areas of interest. This journal has been accepted for indexing on PubMed Central. The manuscript management system is completely online and includes a very quick and fair peer-review system. Visit http://www.dovepress.com/ testimonials.php to read real quotes from published authors.

Submit your manuscript here: http://www.dovepress.com/patient-preference-and-adherence-journal 